\title{
Methyl Iodide Adsorption on Reduced Silver-Functionalized Silica Aerogel: How Temperature Impacts the Adsorption?
}

\author{
Siqi Tang ${ }^{1}$, Seungrag Choi $^{1}$, and Lawrence Tavlarides ${ }^{1}$ \\ ${ }^{1}$ Syracuse University
}

May 26, 2021

\begin{abstract}
To understand the effect of temperature to the adsorption, $104 \mathrm{ppbv}$ and $1044 \mathrm{ppbv}$ methyl iodide $\left(\mathrm{CH}_{3} \mathrm{I}\right)$ adsorptions on reduced silver-functionalized silica aerogel $\left(\mathrm{Ag}^{0}\right.$-Aerogel) at 100,150 and 200 were performed. In the experiments, a significantly high uptake rate $(3-4$ times higher than that at 100 and 150$)$ was observed for the 104 ppbv adsorption at 200 . To explain such behavior, a potential reaction pathway was proposed and multiple physical analyses including nitrogen titration, x-ray photoelectron spectroscopy (XPS) and scanning electron microscopy (SEM) were performed. Based on the results, the contributing factors appear to be the formation of different Ag-I components induced by temperature, higher silver site availability, decreasing diffusion limitation, and increasing reaction rate described by the Arrhenius relationship.
\end{abstract}

Methyl Iodide Adsorption on Reduced Silver- Functionalized Silica Aerogel: How Temperature Impacts the Adsorption?

Siqi Tang, Seungrag Choi, and Lawrence L. Tavlarides*

Department of Biomedical and Chemical Engineering, Syracuse University, 329 Link Hall, Syracuse, NY 13244, USA

\begin{abstract}
To understand the effect of temperature to the adsorption, $104 \mathrm{ppbv}$ and $1044 \mathrm{ppbv}$ methyl iodide $\left(\mathrm{CH}_{3} \mathrm{I}\right)$ adsorptions on reduced silver-functionalized silica aerogel $\left(\mathrm{Ag}^{0}\right.$-Aerogel $)$ at 100,150 and 200 were performed. In the experiments, a significantly high uptake rate (3-4 times higher than that at 100 and 150$)$ was observed for the $104 \mathrm{ppbv}$ adsorption at 200 . To explain such behavior, a potential reaction pathway was proposed and multiple physical analyses including nitrogen titration, x-ray photoelectron spectroscopy (XPS) and scanning electron microscopy (SEM) were performed. Based on the results, the contributing factors appear to be the formation of different Ag-I components induced by temperature, higher silver site availability, decreasing diffusion limitation, and increasing reaction rate described by the Arrhenius relationship.
\end{abstract}

Topical Heading: Separations: Materials, Devices and Processes

Keywords: Adsorption, Iodine Removal, Separation, Silver Aerogel

\section{Introduction}

Since 1951, when the first nuclear power plant was built in Idaho, the nuclear waste treatment arose as a crucial difficulty and environmental concern. ${ }^{1}$ During the nuclear fission and the successive aqueous reprocessing of the radioactive waste, ${ }^{129} \mathrm{I}$ was released in both organic and inorganic forms to off-gas streams, along with ${ }^{85} \mathrm{Kr},{ }^{14} \mathrm{C},{ }^{3} \mathrm{H}$ etc. ${ }^{2-4}$ According to Jubin and Strachan ${ }^{4}$, the radioactive iodine (both inorganic 
and organic forms) mainly exists in dissolve off-gas (DOG) and vessel off-gas (VOG), which contain 5-10 ppmv and 20-30 ppbv respectively. Unlike $\mathrm{I}_{2}$, it is more difficult to study the organic iodides because of their additional alkyl groups and the low concentrations. Multiple forms of organic iodides (from $\mathrm{CH}_{3} \mathrm{I}$ to $\mathrm{C}_{12} \mathrm{H}_{25} \mathrm{I}$ ) were observed, and among these organic iodides, $\mathrm{CH}_{3} \mathrm{I}$ and $\mathrm{C}_{12} \mathrm{H}_{25} \mathrm{I}$ were reported to be the two most abundant ones. ${ }^{5-10}$

To remove the radioactive iodine, multiple adsorbents were developed and studied including reduced silvercontaining materials such as silver functionalized silica aerogel $\left(\mathrm{Ag}^{0} \text {-Aerogel }\right)^{11}$, hydrogen reduced silver exchanged mordenite $\left(\mathrm{Ag}^{0} \mathrm{Z}\right)^{12,13}$, silver nitrate impregnated alumina $(\mathrm{AgA})^{14}$; bismuth-containing mate-

rials such as $\mathrm{Bi}-\mathrm{Bi}_{2} \mathrm{O}_{3}-\mathrm{TiO}_{2}-\mathrm{C}^{15}$, bismuth-decorated electrospinning carbon nanofiber ${ }^{16}$; and other organic materials such as graphene aerogel ${ }^{17}$, nitrogen-rich covalent organic framework (SCU-COF) ${ }^{18}$ and metal organic frameworks $(\mathrm{MOF})^{19}$. Among these materials, the silver-containing ones are the most matured and commonly used. To provide references and information for the design and future industrial application of $\mathrm{Ag}^{0}$-Aerogel, the adsorption experiments of $104 \mathrm{ppbv}$ and $1044 \mathrm{ppbv} \mathrm{CH}_{3} \mathrm{I}$ on $\mathrm{Ag}^{0}$-Aerogel at 100, 150 and 200 were conducted. During the experiments, an abnormally high uptake rate was observed for $104 \mathrm{ppbv}$ $\mathrm{CH}_{3} \mathrm{I}$ adsorption at 200 , and multiple physical analyses including nitrogen titration, scanning electron microscopy (SEM) and x-ray photoelectron spectroscopy (XPS) were performed. Based on the data collected and theoretical analyses, the factors impacting the uptake rate appear to be, unusual reactions and products, difference in silver site availability, change of diffusion limitation and impact of temperature to reaction rate described by the Arrhenius relationship.

\section{Method}

\section{Continuous Flow Adsorption System}

The organic iodide adsorption experiments were performed using a continuous flow adsorption system. The system includes the Dynacalibrator (VICI, Model 450 and 500), adsorption column, furnace, microbalance and the corresponding data acquisition system.

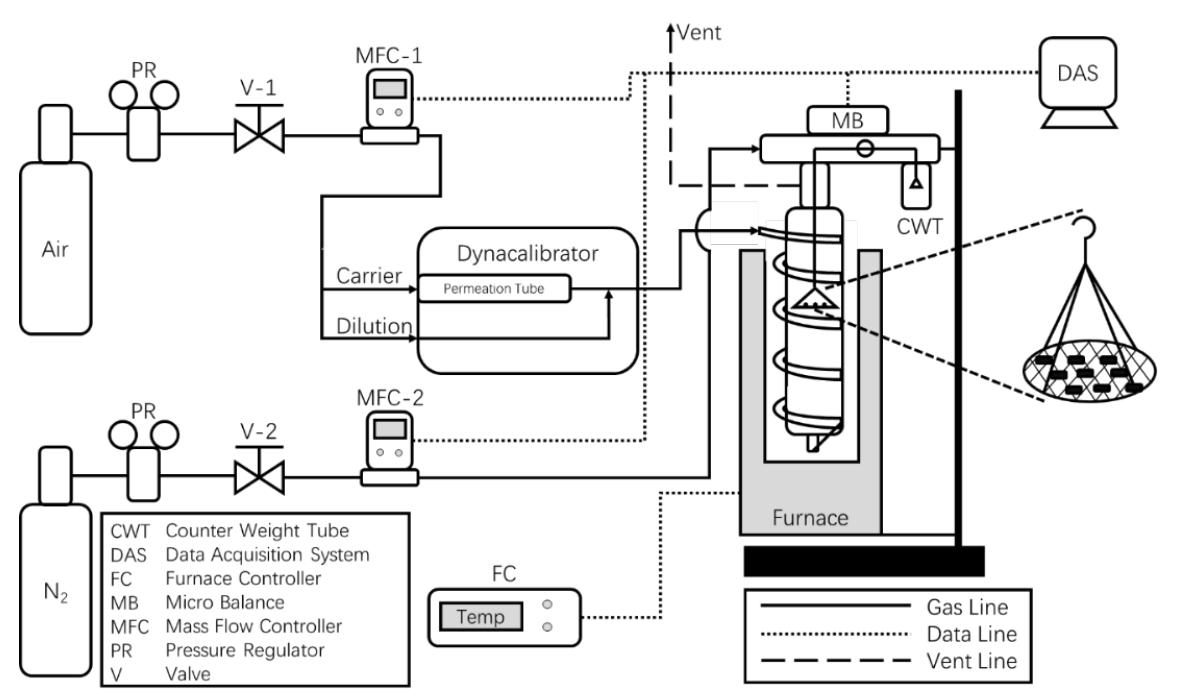

Figure 1. Schematic diagram of the continuous flow adsorption system.

As Figure 1 shows, a permeation tube containing $\mathrm{CH}_{3} \mathrm{I}$ was placed in the Dynacalibrator, which air (Airgas Inc. Air, Ultra Zero) flowed through as the carrier gas. The mixture then passed through the pre-heating coil around the adsorption tube (inner diameter $=30 \mathrm{~mm}$ ) and reached the adsorbent placed in the tray. During 
the adsorption process, the mass change was measured by the microbalance and the data were recorded by the computer.

Additionally, to prevent the counterweight from being oxidized, the continuously flowing nitrogen (Airgas Inc. Nitrogen, Ultra High Purity) was used as the protective gas. The temperature of the adsorption system was controlled by the temperature controller and the connected furnace; the flow rate of the adsorbate mixture was controlled by the mass flow controller.

\section{Silver Functionalized Silica Aerogel}

In this presented work, silver functionalized silica aerogel $\left(\mathrm{Ag}^{0}\right.$-Aerogel $)$ was selected to be the adsorbent for its high silver concentration and high aging resistance. ${ }^{20}$ The shape and size of $\mathrm{Ag}^{0}$-Aerogel is relatively uneven and the average density and diameter of the material is $0.58 \mathrm{~g} / \mathrm{cm}^{3}$ and $0.2 \mathrm{~cm}$, respectively. The iodine adsorption capacity was measured experimentally to be approximately $37-38 \mathrm{wt} \%$.

The compositions of the as-received $\mathrm{Ag}^{0}$-Aerogel measured by SEM-EDX and XPS are listed in Table 1.

\begin{tabular}{llllll}
\hline & $\mathrm{C}(\mathrm{wt} \%)$ & $\mathrm{O}(\mathrm{wt} \%)$ & $\mathrm{Si}(\mathrm{wt} \%)$ & $\mathrm{S}(\mathrm{wt} \%)$ & $\mathrm{Ag}(\mathrm{wt} \%)$ \\
\hline SEM-EDX & 12.0 & 32.5 & 18.3 & 5.7 & 31.5 \\
XPS & 11.2 & 15.4 & 34.5 & 5.2 & 33.7 \\
\hline
\end{tabular}

Table 1. Chemical composition of the $\mathrm{Ag}^{0}$-Aerogel determined by SEM-EDX and XPS.

The results in the first row were measured by Backscattered electron composition (BEC) mode of scanning electron microscopy (SEM, JEOL JSM IT100LA) with energy dispersive x-ray analysis (EDX). During the analysis, unlike reduced silver exchanged mordenite ${ }^{13}$, no obvious silver cluster in micrometer scale was observed on the pellet surface. The second row provides the composition measured by x-ray photoelectron spectroscopy (XPS, Scienta Omicron ESCA-2SR).

The reactions between $\mathrm{Ag}$ and organic iodides were proposed by Scheele et al. ${ }^{21}$; using $\mathrm{CH}_{3} \mathrm{I}$ as an example, the reaction is, $2 \mathrm{Ag}+2 \mathrm{CH}_{3} \mathrm{I}(\mathrm{g}) \leftrightarrow 2 \mathrm{AgI}+\mathrm{C}_{2} \mathrm{H}_{6}(\mathrm{~g})$. In this reaction, iodine binds with silver and the organic groups are released to the off-stream in gas form, which was also suggested by Zhou et al. ${ }^{22}$

\section{Procedure Description}

Using the continuous flow adsorption system, the mass changes of $\mathrm{Ag}^{0}$-Aerogel were recorded and the kinetic adsorption curves can be generated. In this presented work, the adsorption experiments of 104 ppbv and 1044 ppbv of $\mathrm{CH}_{3} \mathrm{I}$ at 100, 150 and 200 were performed. Since reaching equilibrium is not realistic at ppbv level concentrations, the experiments were stopped at approximately 300 hours. ${ }^{23}$ To satisfy the superficial velocity of $1.1 \mathrm{~m} / \mathrm{min},{ }^{24}$ the flow rate of the gas through the adsorption column was set at $500 \mathrm{sccm}$ (standard cubic centimeter per minute) for all experiments. Additionally, to prevent the concentration difference between the pellets, a single layer of $\mathrm{Ag}^{0}$-Aerogel (0.1-0.2 g) was carefully placed in the tray.

Before the start of the organic iodide adsorption, the pellets were air-dried at the same temperature as that of the adsorption experiment until the mass change in the past 24 hours is lower than 0.005 wt\% (approximately $1 / 5$ of the adsorption rate of $104 \mathrm{ppbv} \mathrm{CH}_{3} \mathrm{I}$ at 150 ). Especially, at 200, the drying process induced the loss of organic moiety of up to $9-10 \mathrm{wt} \%$, which a similar observation was reported in Matyáš and Engler's thermogravimetric analysis (TGA). ${ }^{25}$

Therefore, to determine the effect of organic moiety loss, the comparison experiments were performed at 104 ppbv- $\mathrm{CH}_{3} \mathrm{I}-150$ and 1044 ppbv- $\mathrm{CH}_{3} \mathrm{I}-150$ using the $\mathrm{Ag}^{0}$-Aerogel with and without the organic moiety loss. The results showed no significant difference in the uptake curves (in wt\%). To further accelerate the drying process (which usually takes weeks) and removing the organic moiety for all experiments, the pellets were vacuum dried overnight at 350 using the degas function of Surface Area and Porosity Analyzer 
(Micromeritics, ASAP 2020) and stored in $\mathrm{N}_{2}$ after the treatment. Similarly, after degassing, the adsorption curves (in wt\%) and the maximum iodine capacities (approximately $37-38 \mathrm{wt} \%$, measured by $50 \mathrm{ppmv} \mathrm{I}_{2}$ adsorption at 150 ) are similar to the untreated adsorbent. It is important to notice that during the 350 treatment, the organic moiety loss results in approximately $10 \%$ loss of pellet mass. Therefore, the similar uptake rate by pellet mass indicates an approximately $10 \%$ loss of uptake rate by silver mass. However, this loss could be considered as a 'worthy cost' due to the successive significant increase of the organic iodide uptake rate at 200 , which will be discussed in the following sections.

\section{Results and Discussion}

\section{Adsorption Kinetics}

The 104 ppbv and 1044 ppbv $\mathrm{CH}_{3} \mathrm{I}$ adsorptions on $\mathrm{Ag}^{0}$-Aerogel at 100, 150 and 200 were performed using the continuous flow adsorption system. For consistency purposes, pellets used for all trials were vacuum dried at 350 before the adsorption. After the pre-dry process, the pellets were moved to the adsorption system and the final water equilibrium process was performed before starting the adsorption. Once the mass change of the pellets in the past $24 \mathrm{~h}$ was less than $0.005 \mathrm{wt} \%$, the $\mathrm{CH}_{3} \mathrm{I}$ adsorption was started. During the $\mathrm{CH}_{3} \mathrm{I}$ adsorption, no significant mass gain/loss was observed neither in the initial part (first 1-2 days) nor after the adsorption ended and the desorption started, which indicating the physisorption of $\mathrm{CH}_{3} \mathrm{I}$ on $\mathrm{Ag}^{0}$-Aerogel is relatively minor.

The kinetic curves are shown in Figure 2, at 100 and 150 , the tendency agrees well with the previous studies of $\mathrm{I}_{2}$ adsorption on $\mathrm{Ag}^{0} \mathrm{Z}^{24}$, that the adsorption rates increase slightly as the temperature increases. However, at 200 , the uptake rate increases significantly (3-4 times higher) at 104 ppbv, and the curvature of the curve decreases at 1044 ppbv. To analyze such abnormal behaviors, the shrinking core model (SCM) was applied.
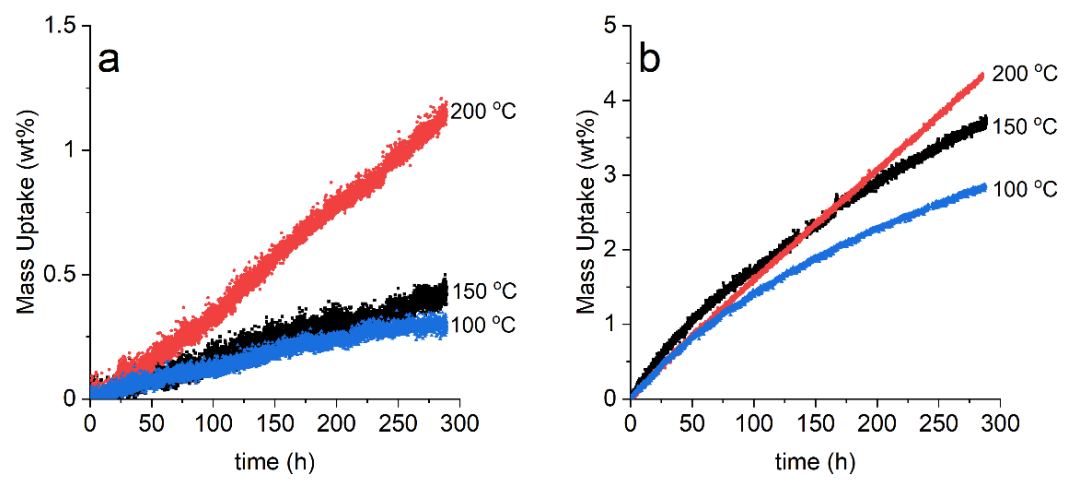

Figure 2. The adsorption curves of $104 \mathrm{ppbv}$ (a) and $1044 \mathrm{ppbv}$ (b) at 100, 150 and 200 .

The SCM (Eq. 1) consists of three terms, the gas film diffusion term (Eq. 2), the pore diffusion term (Eq. 3 ) and the reaction term (Eq. 4). ${ }^{26}$

$q$ is the average sorbate concentration $(\mathrm{mol} / \mathrm{g})$ at time $t(\mathrm{~s})$ and $q_{e}$ is the equilibrium sorbate concentration $(\mathrm{mol} / \mathrm{g}), \tau_{1}, \tau_{2}$, and $\tau_{3}$ are gas film diffusion term, pore diffusion term, and reaction term respectively, $R_{a}$ is the radius of the pellet $(\mathrm{cm}), \rho_{\pi}$ is the density of the pellet $\left(\mathrm{g} / \mathrm{cm}^{3}\right), C_{b}$ is the bulk adsorbate concentration $\left(\mathrm{mol} / \mathrm{cm}^{3}\right), k_{f}$ is the gas film mass transfer coefficient $(\mathrm{cm} / \mathrm{s}), D_{p}$ is the pore diffusivity $\left(\mathrm{cm}^{2} / \mathrm{s}\right), k_{s}$ is the reaction rate constant $(\mathrm{cm} / \mathrm{s})$ and $b$ is the stoichiometric coefficient of $\mathrm{Ag}$ in $\mathrm{Ag}-\mathrm{CH}_{3} \mathrm{I}$ reaction, which is 1. Additionally, $q$ and $q_{e}$ are sometimes represented in wt\% for convenience.

The $k_{f}$ in Eq. 2 can be approximated theoretically using Eq. $5-8 .{ }^{24}$ 
$S h, S c$, and $R e$ are Sherwood number, Schmidt number, and Reynolds number respectively, $D_{A B}$ is the binary diffusivity $\left(\mathrm{cm}^{2} / \mathrm{s}\right), T$ is the temperature $(\mathrm{K}), P$ is the pressure (bar), $M$ is the molecular mass of $\mathrm{CH}_{3} \mathrm{I}(\mathrm{A})$ and air (B). $\nu$ is the atomic diffusion volume $\left(\mathrm{cm}^{3}\right)$, which $=52.63 \mathrm{~cm}^{3}$ and $=19.7 \mathrm{~cm}^{3} .{ }^{27}$

The $A A R D$ 's (absolute average relative deviation) were determined using Eq. 9,

where $N$ is the number of data points and exp, model denote the experiment results and model fitting results.

The parameters and results determined using the SCM are listed in Table 2. At $104 \mathrm{ppbv}$, the $D_{p}$ 's were not determined since no significant pore diffusion processes were observed during the experiments.

\begin{tabular}{lll}
\hline Concentration (ppbv) & Temperature () & $k_{f}(\mathrm{~cm} / \mathrm{s})$ \\
\hline 104 & 100 & $2.18^{*}$ \\
& 150 & $2.71^{*}$ \\
1044 & 200 & $3.29^{*}$ \\
& 100 & $2.18^{*}$ \\
& 150 & $2.71^{*}$ \\
& 200 & $3.29^{*}$
\end{tabular}

Calculated theoretically using Eq. 5-8. $\quad{ }^{*}$ Calculated theoretically using Eq. 5-8. $\quad{ }^{*}$ Calculated theoretically using Eq. 5-8. Not determined.

Table 2. Parameters and results of the SCM.

It can be visualized that, at 200 , certain abnormal behaviors exist for both 104 and 1044 ppbv $\mathrm{CH}_{3} \mathrm{I}$ adsorption. To explain such observation, the nitrogen titration, XPS and SEM-EDX analyses were performed and a potential reaction pathway was proposed.

\section{Water Equilibrium in Drying Process}

Because of multiple factors including the pellet size of $\mathrm{Ag}^{0}$-Aerogel, the internal structure of $\mathrm{Ag}^{0}$-Aerogel, etc., the water concentration in the pellets after 350 vacuum drying may not be constant. Therefore, a final drying is still required before the $\mathrm{CH}_{3} \mathrm{I}$ adsorption and the pellets may adsorb or desorb water in different trials. The water adsorbed was from the trace amount of moisture contained in the carrier gas (Airgas Inc. Air, Ultra Zero). According to the manufacturer, the air contains approximately 2 ppmv of water and the value was also validated by experimental measurement using a dewpoint meter. By selecting a water adsorption curve with the highest uptake (therefore the initial water concentration in the pellet can be assumed to be zero), the water adsorption process can be modeled using multiple models including the 1-D spherical Fick's Law ${ }^{26}$ (Eq. 10), differential form of the diffusion term of the shrinking core model (SCM) ${ }^{26}$ (Eq. 11), and the micropore term of the pore diffusion model (Micro PD $)^{13}$ (Eq. 12). For Fick's law and the shrinking core model, it is assumed that an equilibrium is established on the surface immediately.

$q(r, t)$ is the sorbate concentration $\left(\mathrm{mol} / \mathrm{cm}^{3}\right)$ at radius $r(\mathrm{~cm})$ at time $t(\mathrm{~s})$, and the average sorbate concentration $q(t)$ can be calculated using. $D$ is the pore diffusivity $\left(\mathrm{cm}^{2} / \mathrm{s}\right), r$ is the radius at timet , $V$ is the volume of the pellet $(\mathrm{cm}), D_{i}$ is the micropore diffusivity $\left(\mathrm{cm}^{2} / \mathrm{s}\right)$ and $R_{i}$ is the radius of the micropore $(\mathrm{cm}) . \quad R_{i}$ was measured by the nitrogen adsorption method using ASAP 2020 and the value is approximately 6.6 . 


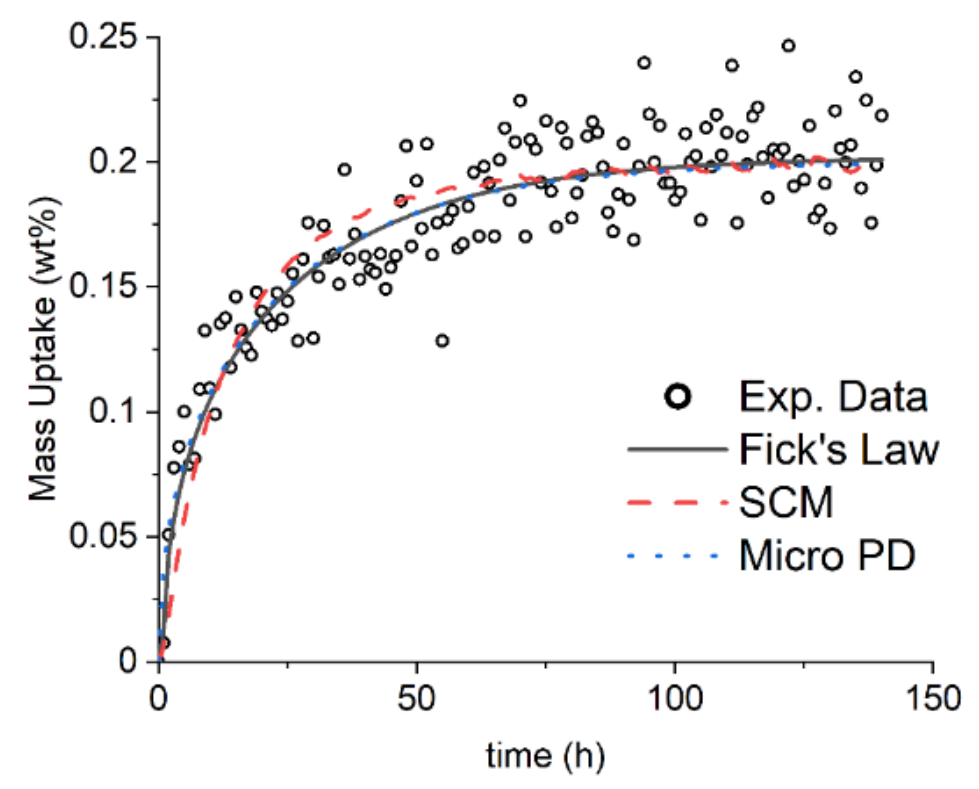

Figure 3. The adsorption curve and the modeling results of the water adsorption process. (Fick's Law and Micro PD are overlapped)

The adsorption curve and the modeling results are shown in Figure 3. The diffusivities determine using Fick's Law, SCM and Micro PD are $9.6 \times 10^{-9} \mathrm{~cm}^{2} / \mathrm{s}, 2.6 \times 10^{-8} \mathrm{~cm}^{2} / \mathrm{s}$ and $4.4 \times 10^{-21} \mathrm{~cm}^{2} / \mathrm{s}$ respectively. By comparing with multiple literature works ${ }^{28,29}$, the values of the diffusivities clearly fit in the range of micropore diffusion, indicating that the water adsorption/desorption in $\mathrm{Ag}^{0}$-Aerogel is a micropore diffusion process.

\section{Nitrogen Adsorption Analyses}

Since the carrier gas contains approximately $2 \mathrm{ppmv}$ of water, the $\mathrm{Ag}^{0}$-Aerogel tends to reach moisture equilibrium with the ambient air during the adsorption of $\mathrm{CH}_{3} \mathrm{I}$. The moisture levels in the pellet at 100 , 150, 200 were measured using the pre-dried pellet and the continuous flow adsorption system. The pre-dried (350 degassed) pellets were placed into the adsorption system with identical settings except flowing pure air instead of air $/ \mathrm{CH}_{3} \mathrm{I}$ mixture. The temperature of the adsorption column was firstly set at 200 , and the pellets started to adsorb water from the ambient air, with the mass change collected continuously. Once the mass change in the past $24 \mathrm{~h}$ was less than $0.005 \mathrm{wt} \%$, the temperature was decreased to 150 and further down to 100 when the same criterion was met. The time to settle a new equilibrium was $100-150$ hours.

The results indicated that the differences in water concentration between each temperature were approximately $0.15-0.2 \mathrm{wt} \%$. In other words, if the water concentration in the pellets at 200 was set as the zero point, the water adsorbed at 150 and 100 were approximately 0.2 and $0.4 \mathrm{wt} \%$. To examine such observation, the water desorption experiment in the reverse temperature order was also performed and the differences between each level were comparable.

In order to determine the effect of different concentrations of moisture in the pellets at various temperatures, the nitrogen adsorption analyses were performed using the Surface Area and Porosity Analyzer (Micromeritics, ASAP 2020). Traditionally, the samples used for nitrogen adsorption analysis were fully dried to prevent any residual water to influence the results. Since the standard drying conditions for $\mathrm{Ag}^{0}$-Aerogel were not 
reported, the fully dried result was the one with the highest pore volume and surface area, selected from multiple 350 degassed trials.

Instead, to determine the surface area and pore volume at real adsorption temperatures, the $\mathrm{Ag}^{0}$-Aerogel was air dried using the adsorption column at the target temperatures (100, 150 and 200$)$ with the same criterion described above. Once the drying process was completed, the pellets were transferred to ASAP 2020 as quickly as possible (2-3 min). To minimize the potential water gain/loss during the analyses, multiple methods were applied including, minimize the time of transferring sample, measure the free volume of the test tube in advance (therefore, exposing the dried sample under vacuum at room temperature could be avoided), submerge the sample in liquid nitrogen immediately, only start the vacuum pump after the sample was submerged, and minimize the analysis time by selecting the minimal amount of sample points. Once the analysis was completed, the sample was transferred back to the adsorption column to measure the mass change during the porosity analysis. Since no significant mass changes were observed, the water gain/loss during the analysis appears to be minor.

As a reference of the highest level of water that could be contained in the pellet during actual industrial usage, the nitrogen adsorption experiment without any sample pretreatment was also performed using normally stored $\mathrm{Ag}^{0}$-Aerogel (named as Room Condition Equilibrium in Figure 4, short as RC.EQ). The storage conditions measured by laboratory thermometer and hydrometer are, $20-23$ and $20-30 \%$ humidity.

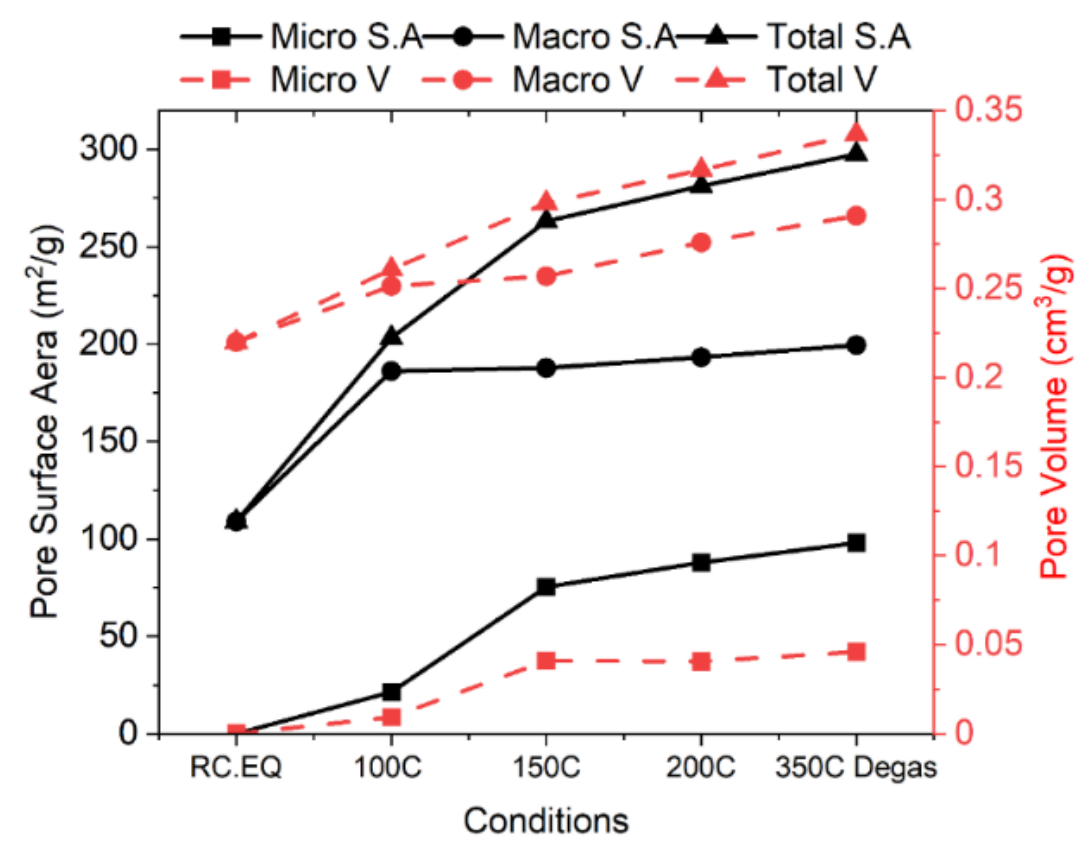

Figure 4. The surface area and pore volume of micropores, macropores and total pores measured using nitrogen titration method at different drying conditions.

The micro, macro and total pore surface area and volume are plotted in Figure 4 . The total pore surface area of the 350 degassed sample is $297.6 \mathrm{~m}^{2} / \mathrm{g}$ and the total pore volume is $0.34 \mathrm{~cm}^{3} / \mathrm{g}$, which are comparable with the trends of surface area and pore volume to silver composition in silica aerogel reported by Balkis Ameen et al. ${ }^{30}$ Additionally, the plot shows that as the temperature decreases and the in-pellet water concentration increases, both pore surface area and pore volume decrease. As the temperature decreases to 100 , the micropores are significantly blocked by water and become fully blocked at room condition equilibrium.

Moreover, the diffusion of $\mathrm{CH}_{3} \mathrm{I}$ and related gas form products in $\mathrm{Ag}^{0}$-Aerogel may also be impacted by the 
porosity change. The porosity ( $\epsilon=$ total pore volume / density) of the pellet is larger at higher temperature, and an experimental relationship between pore diffusivity and porosity is given as, ${ }^{31}$

where $m$ is usually between $2-4.5$ depending on the material. This relationship indicates that the pore diffusivity of both $\mathrm{CH}_{3} \mathrm{I}$ and gas form products may increase with increasing temperature, and therefore decreasing the diffusion limitations and accelerating the adsorption process.

\section{Pore Distribution and Silver Sites Availability}

Shown in Figure 4, the drying temperature impacts the pore surface area and the pore volume of the pellets by changing the water concentration in the pellet. When temperature decreases to below 100 , the micropores are significantly impacted. This can be further visualized by comparing the pore distribution plots of the Barrett-Joyner-Halenda (BJH) desorption method and the density function theory (DFT) of 350 degassed and room condition equilibrium samples.

The pore distribution plots (Figure 5) show that the $\mathrm{Ag}^{0}$-Aerogel mostly consists of mesopores (20-500) and micropores $(<20)$ with a limited amount of macropores $(>500)$, which agree with the SEM images that no significant structure was observed in the micrometer scale. Comparing the two curves in Figure 5. b, two sharp peaks at approximately 6 and 12 were observed only in the fully dried sample, whereas the room condition equilibrium one only contained a small peak at 15-17. A similar trend is also revealed in Figure 5. a: the 350 degassed sample contains a 'tail' at 20-25 .

Such observation further supports that the micropores $(<2 \mathrm{~nm})$ are mostly blocked as the in-pellet water concentration increases (Discussed in Nitrogen Adsorption Analyses) and the water adsorption/desorption process in $\mathrm{Ag}^{0}$-Aerogel is a micropore diffusion process (Discussed in Water Equilibrium in Drying Process ) .
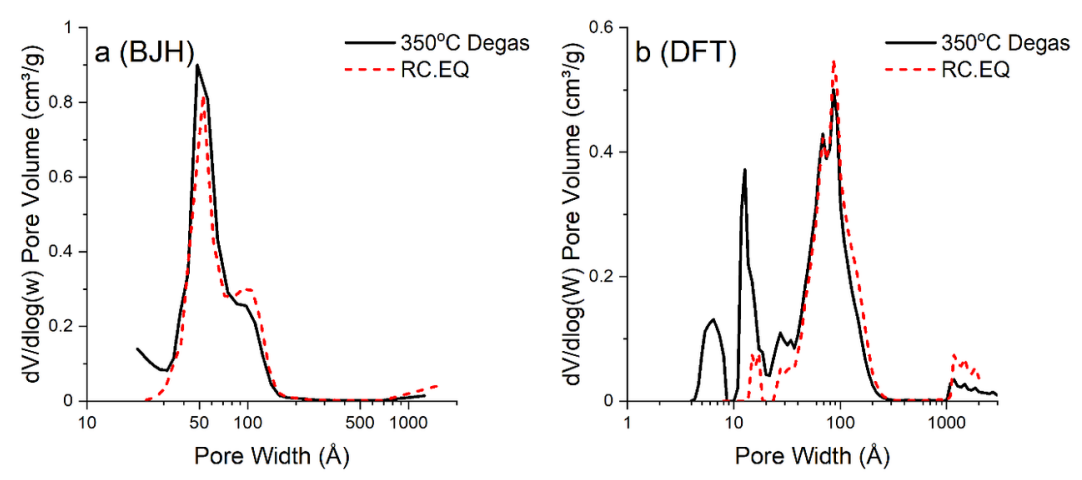

Figure 5. The BJH (a) and DFT (b) pore distribution plots of 350 degassed sample and room condition equilibrium (RC.EQ).

Since both pore surface area, pore volume and the amount of micropores decrease as the adsorption temperature decreases, the availability of silver sites may decrease due to the increasing water coverage.

\section{Potential Reaction Pathway and Diffusion Limitation}

For the chemisorption with gas phase product generated, Zhou and White ${ }^{32}$ and Robb and Harriott ${ }^{33}$ suggested that the formation of gases and the successive diffusion limitations may result in a fractional order reaction, which has been observed in the $\mathrm{CH}_{3} \mathrm{I}$ adsorption on $\mathrm{Ag}^{0}$-Aerogel by Tang et al. ${ }^{23}$ To explain this observation, a potential reaction pathway is proposed. 


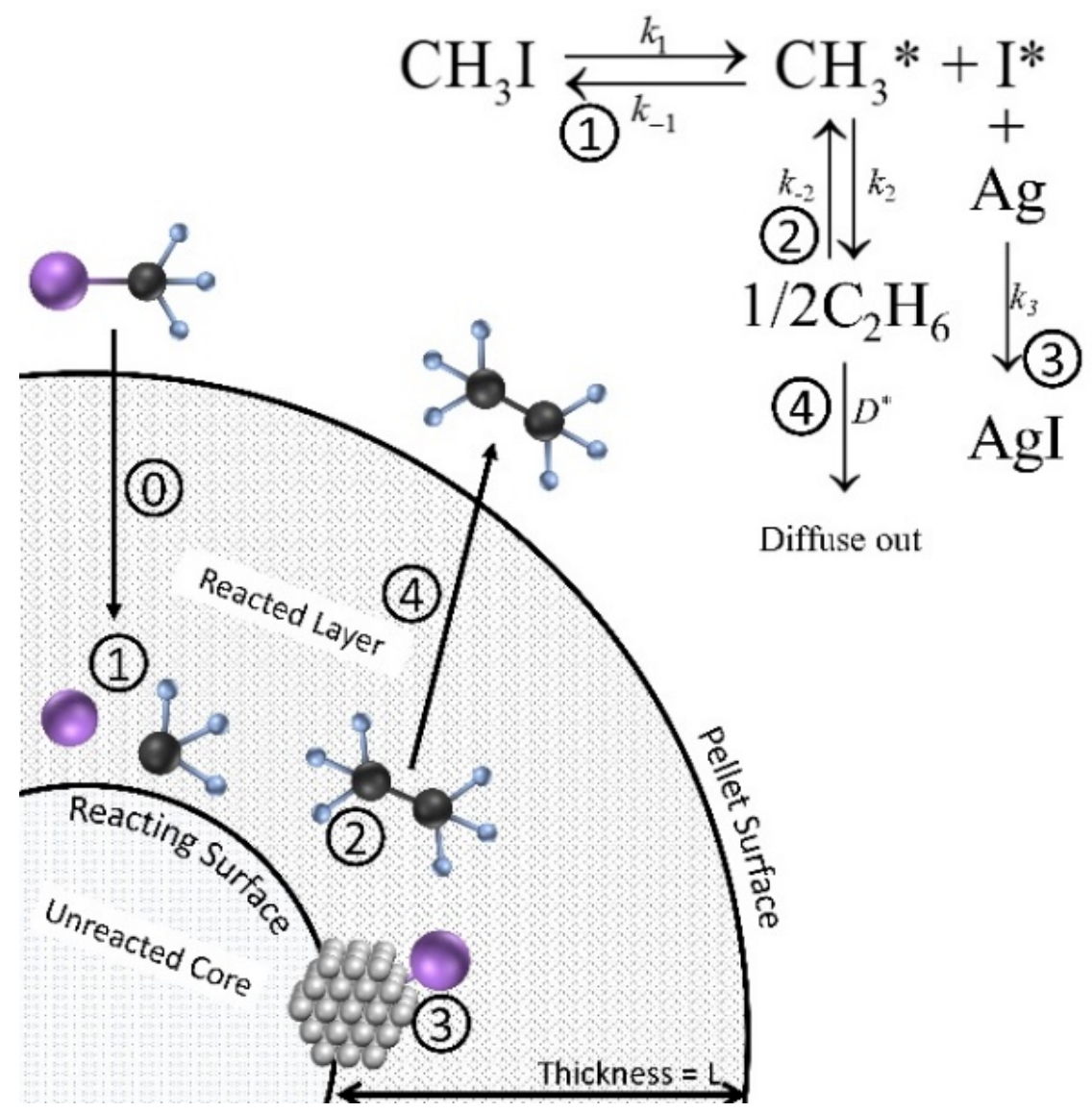

Figure 6. The proposed reaction pathway between $\mathrm{CH}_{3} \mathrm{I}$ and $\mathrm{Ag}$ in $\mathrm{Ag}^{0}$-Aerogel.

In the shrinking core model, the reactions only happen on the reacting surface, which separates the reacted layer and the unreacted core. Once the $\mathrm{Ag}$ sites on one surface are fully consumed, the reactions proceed to the next surface. As Figure 6 shown, during the adsorption, $\mathrm{CH}_{3} \mathrm{I}$ first diffuses through the reacted layer and reaches the reacting surface (0). On the reacting surface, $\mathrm{CH}_{3} \mathrm{I}$ breaks reversibly into two free radicals (1), $\mathrm{CH}_{3}{ }^{*}$ and I ${ }^{*}$. Two $\mathrm{CH}_{3}{ }^{*}$ radicals bind with each other and form $\mathrm{C}_{2} \mathrm{H}_{6}$ (2); I*adical binds with $\mathrm{Ag}$ and forms $\mathrm{AgI}(3)$; and $\mathrm{C}_{2} \mathrm{H}_{6}$ diffuses out through the reacted layer (4). In this process, to satisfy the observed 1.4 reaction order by Tang et al. ${ }^{23}$, the reaction order of $\mathrm{CH}_{3} \mathrm{I}$ is assumed to be $n$; the orders of other reactions are 1 to each component; and the reason will be discussed in the following contents.

The formation/consumption rates of the components can be written as,

where $k$ 's are the reaction rate constant, $D^{*}$ is the diffusivity of $\mathrm{C}_{2} \mathrm{H}_{6}$, and $L$ is the thickness of the reacted layer. The stoichiometric coeffecient of $\mathrm{C}_{2} \mathrm{H}_{6}$ is ignored in the equations since it does not impact the results.

Assuming pseudo-equilibrium, the steady state is established immediately after the reactions proceed to the next surface, $\mathrm{CH}_{3}{ }^{*}, \mathrm{I}^{*}$ and $\mathrm{C}_{2} \mathrm{H}_{6}$ may not accumulate on the reacting surface and the rates, , , and should be 0. Therefore, the and in Eq. 14 can be rewritten in term of constants and (the detailed procedure can be found in the Supplementary Materials ) which is,

where $\Phi$ is similar to the Thiele modulus, the ratio of the reaction rate to the diffusion rate. ${ }^{34}$ 
As more than five parameters are included, determining the step-wise would be impracticable. Considering two limiting cases, when, the reaction rate would be proportional to; if, would be proportional to. Since the reaction order would be between $n / 2$ and $n$, the integer that satisfies the observed 1.4 order is $n=2$.

Additionally, Eq. 18 indicates that the temperature change may impact the reaction rate. Generally, the relationship between $k$ (or $D$ ) and $T$ can be written as Eq. 20,

which implies that the temperature change may impact the overall reaction rate by changing the magnitude of .

\section{Arrhenius Relationship and Eyring Equation}

The well-known Arrhenius relationship is commonly used in describing the temperature dependence of reaction rate constant and diffusivity, which is, ${ }^{35}$

and the linear form is,

Where $k_{s}{ }^{0}$ is the pre-exponential factor (unit same as $k_{s}$ ), $\Delta E$ is the activation energy $(\mathrm{kJ} / \mathrm{mol}$ ) and $R$ is the gas constant $(\mathrm{kJ} / \mathrm{mol} / \mathrm{K})$. Reported by Tang et al. ${ }^{23}$, the $\mathrm{CH}_{3} \mathrm{I}$ adsorption on $\mathrm{Ag}^{0}$-Aerogel may be a 1.4 order shrinking core process, where the calibrated $k_{s}{ }^{*}\left((\mathrm{~cm} / \mathrm{s})[?]\left(\mathrm{mol} / \mathrm{cm}^{3}\right)^{1-\mathrm{n}}\right)$ can be represented as . Therefore, the Arrhenius equation was applied to the calibrated $k_{s}{ }^{*}$ and the plot including the fitting results are shown in Figure 7.

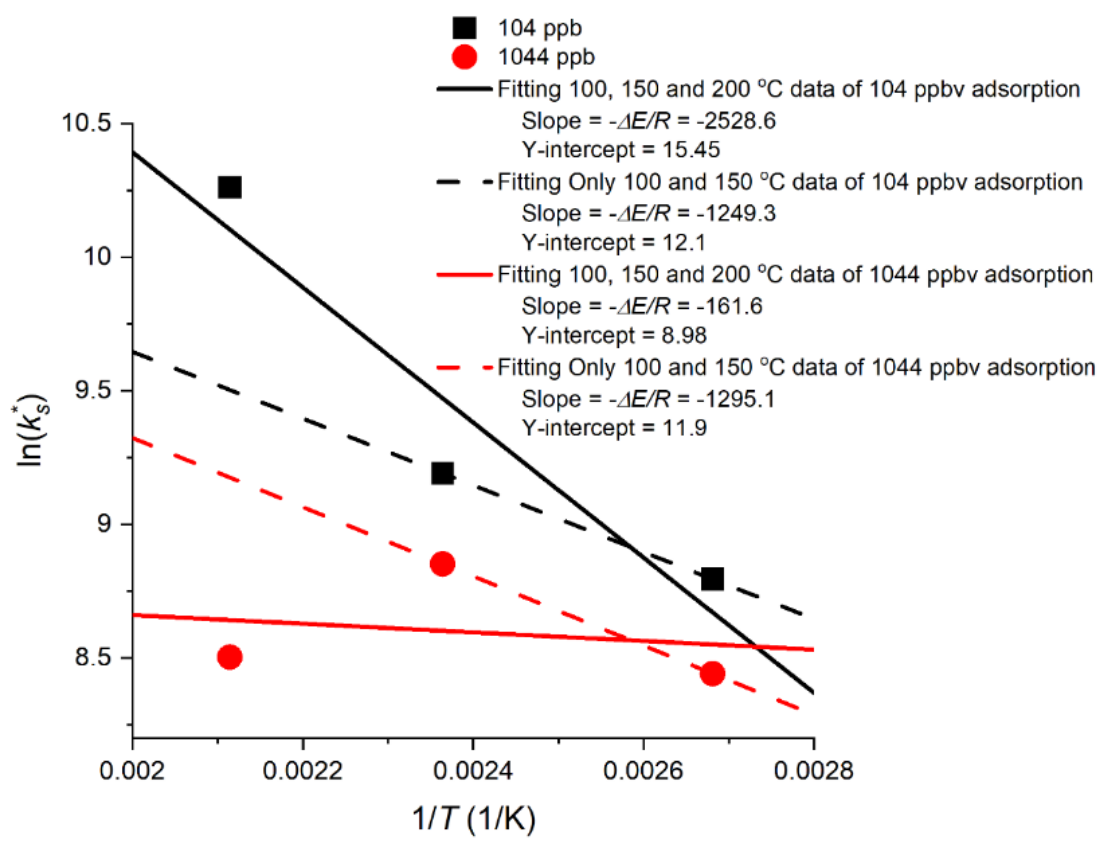

Figure 7. The Arrhenius plot of 104 and 1044 ppbv $\mathrm{CH}_{3} \mathrm{I}$ adsorptions on $\mathrm{Ag}^{0}$-Aerogel at 100, 150 and 200 .

By fitting all three data points at each concentration, the $\Delta E$ 's are 21.0 and $1.34 \mathrm{~kJ} / \mathrm{mol}$ for 104 and 1044 ppbv adsorptions respectively. As stated above, both adsorption behaviors at 200 are relatively abnormal. If excluding the 200 data and consider the 100 and 150 results only, the $\Delta E$ 's of 104 and 1044 ppbv adsorptions are well-agreed. The activation energy determined using 100 and 150 data of 104 ppbv adsorption is 10.4 $\mathrm{kJ} / \mathrm{mol}$, that of $1044 \mathrm{ppbv}$ adsorption is $10.8 \mathrm{~kJ} / \mathrm{mol}$ and the pre-exponential factors are $1.80 \times 10^{5}$ and $1.47 \times 10^{5}(\mathrm{~cm} / \mathrm{s})[?]\left(\mathrm{mol} / \mathrm{cm}^{3}\right)^{1-\mathrm{n}}$ respectively. In previous studies of $\mathrm{CH}_{3} \mathrm{I}$ adsorption on Ag-ZSM-5, Park et 
al. ${ }^{36}$ report the activation energy of $2.57 \mathrm{~kJ} / \mathrm{mol}$ and Scheele et al. ${ }^{21}$ proposed $20-40 \mathrm{~kJ} / \mathrm{mol}$ for $\mathrm{CH}_{3} \mathrm{I}$ adsorption on $\mathrm{Ag}^{0} \mathrm{Z}$.

Another model describing the relationship between temperature and reaction rate constant is the Eyring equation, ${ }^{37}$

where $k$ is the reaction rate $\left(\mathrm{s}^{-1}\right), k_{B}$ is Boltzmann's constant, $h$ is Planck's constant and $\Delta \Gamma$ is the Gibbs free energy of activation. Since the unit and the physical meaning of $k$ are different from $k_{s}$ determined using SCM, a quantified result may not be given. However, some valuable trends and predictions can be interpreted. Representing the Gibbs free energy of the activation of the reaction between iodoalkane and $\operatorname{Ag}^{0}$-Aerogel as $\Delta \Gamma, d k / d T$ may be written as,

Eq. 24 indicates that the dependency of $k$ to $T$ may vary as $\Delta \Gamma / P$ changes. For example, given a range of temperature $T_{1}$ to $T_{3}$, Figure 8 shows that how $-\Delta \Gamma / P$ changes the dependency of $k$ to $T$. When $-\Delta \Gamma / P$ $<T_{1}, d k / d T>0$, indicating the increasing temperature increases the reaction rate; when $-\Delta \Gamma / P>T_{3}$, $d k / d T<0$, and the reaction rate may decrease with increasing temperature. Interestingly, if $T_{1}<-\Delta \Gamma / P$ $<T_{3}$, a minimum value of $k$ may be observed at $T=-\Delta \Gamma / P$. Generally, the $\Delta \Gamma$ is represented as a positive number, but can it be negative in some circumstances?

Proposed in the section above, iodoalkane molecules may cleave into free radicals and produce alkanes and AgI in the re-bindings of radicals. The negative activation energies have been reported in some radicalsengaged reactions. ${ }^{38,39}$ Therefore, in the adsorptions of iodoalkanes with larger alkane groups (e.g. $\mathrm{C}_{6} \mathrm{H}_{13} \mathrm{I}$, $\mathrm{C}_{12} \mathrm{H}_{25} \mathrm{I}$, etc.), the $\Delta \Gamma$ 's may decrease (or become negative) due to their instabilities, ${ }^{40}$ and the rough estimation above suggests that the dependency of $k$ to $T$ may vary at certain circumstances.

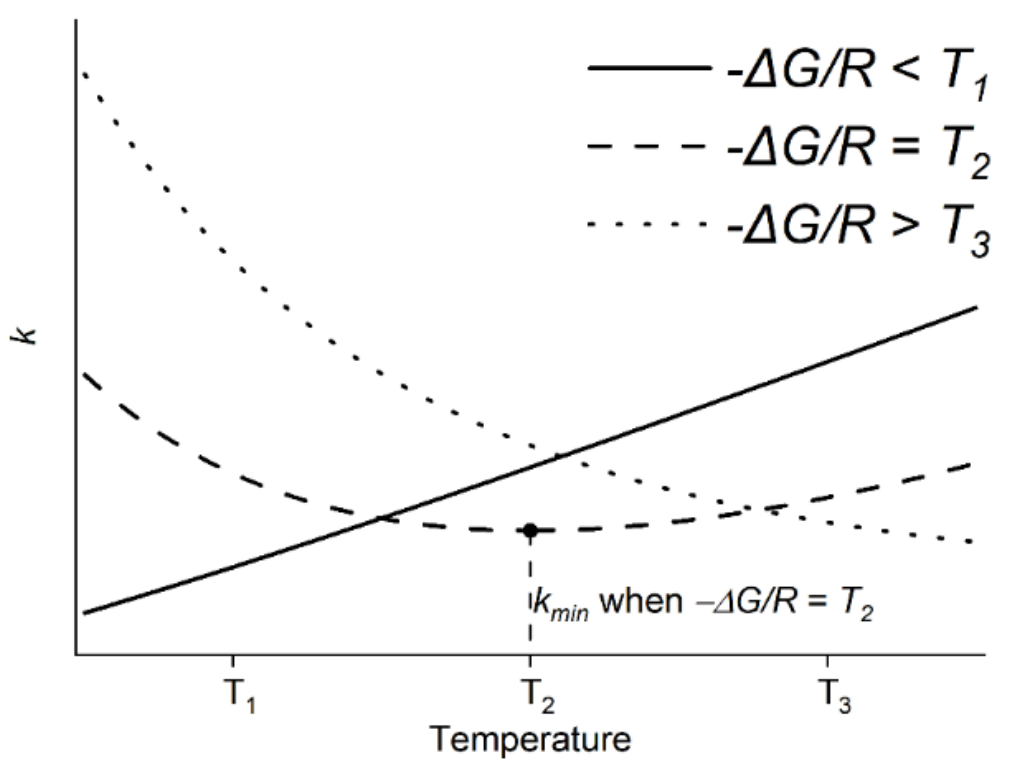

Figure 8. An example of the Eyring equation, how $\Delta \Gamma / P$ changes the dependency of $k$ to $T$ (curves have been rescaled and repositioned to clarify the tendencies).

\section{XPS and SEM-EDX Analyses}

To determine the compounds formed during the adsorptions, XPS analyses were performed using, fresh $\mathrm{Ag}^{0}$-Aerogel, 350 degassed $\mathrm{Ag}^{0}$-Aerogel, $\mathrm{CH}_{3} \mathrm{I}$ fully loaded (9585 ppbv, powdered adsorbent) $\mathrm{Ag}^{0}$-Aerogel, 
$\mathrm{I}_{2}$ fully loaded (50 ppmv, powdered adsorbent) $\mathrm{Ag}^{0}$-Aerogel, 104 ppbv $\mathrm{CH}_{3} \mathrm{I}$ adsorbed (partially loaded) $\mathrm{Ag}^{0}$-Aerogel at 100, 150 and 200 , and $1044 \mathrm{ppbv} \mathrm{CH}_{3} \mathrm{I}$ adsorbed (partially loaded) $\mathrm{Ag}^{0}$-Aerogel at the same temperatures. Since the first scan of the $104 \mathrm{ppbv} / 200$ was questionable, a rescan was performed using the identical sample and settings (marked as $\mathrm{SC} 1$ and $\mathrm{SC} 2$ in the spectra).

The XPS analyses were performed using the Scienta Omicron ESCA-2SR at Cornell University. The operating pressure is $1 \times 10^{-9}$ Torr, and the monochromatic $\mathrm{Al} \mathrm{K \alpha}$ x-rays $(1486.6 \mathrm{eV})$ were generated at $300 \mathrm{~W}(15$ $\mathrm{kV} ; 20 \mathrm{~mA})$.
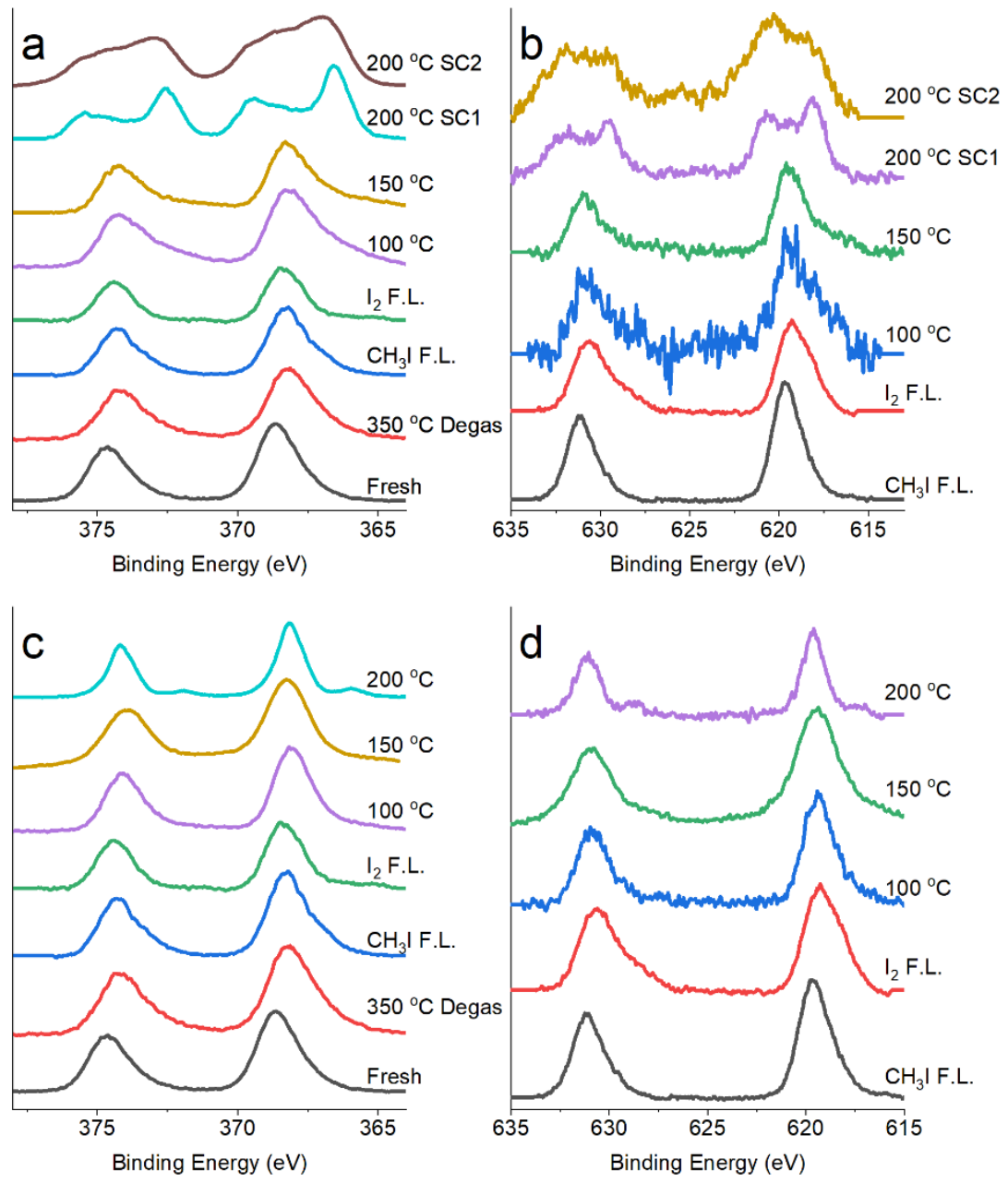

Figure 9. Regional scans of $\mathrm{Ag}$ (a), I (b) XPS spectra of 104 ppbv $\mathrm{CH}_{3} \mathrm{I}$ adsorbed $\mathrm{Ag}^{0}$-Aerogel and $\mathrm{Ag}$ (c), $\mathrm{I}(\mathrm{d})$ of $1044 \mathrm{ppbv} \mathrm{CH}_{3} \mathrm{I}$ adsorbed $\mathrm{Ag}^{0}$-Aerogel, with fresh, 350 degassed, $\mathrm{CH}_{3} \mathrm{I}$ fully loaded at 150 and $\mathrm{I}_{2}$ fully loaded $\mathrm{Ag}^{0}$-Aerogel at 150 as references.

The XPS spectra collected are shown in Figure 9. The fresh $\mathrm{Ag}^{0}$-Aerogel obtains the $\mathrm{Ag} 3 \mathrm{~d}_{5 / 2}$ peak located at approximately $368.6 \mathrm{eV}$ and the $\mathrm{Ag} 3 \mathrm{~d}_{3 / 2}$ peak at approximately $374.6 \mathrm{eV}$, which are comparable to 
the binding energy (BE) reported by Matyáš et al. ${ }^{20}$ After being degassed at 350 , the Ag BE decreases to 368.1 and $374.1 \mathrm{eV}$, indicating that certain amount of $\mathrm{Ag}_{2} \mathrm{~S}$ nanoparticles may be generated in this process. ${ }^{41,42}$ After reacting with $\mathrm{CH}_{3} \mathrm{I}$ at different concentrations and temperatures, most of the $\mathrm{Ag}$ peaks shift to approximately 368.2 and $374.2 \mathrm{eV}$ except those of the pellets at $104 \mathrm{ppbv} / 200$ condition. The trend of iodine $\mathrm{BE}$ is slightly different from that of $\mathrm{Ag}, \mathrm{CH}_{3} \mathrm{I}$ fully loaded sample contains the $\mathrm{I}_{3} \mathrm{~d}_{5 / 2}$ and $\mathrm{I}_{3} \mathrm{~d}_{3 / 2}$ peaks at approximately 619.6 and $631.1 \mathrm{eV}$ respectively, $\mathrm{I}_{2}$ fully loaded sample contains $\mathrm{I}_{3} \mathrm{~d}_{5 / 2}$ and $\mathrm{I}_{3} \mathrm{~d}_{3 / 2}$ peaks at approximately 619.3 and $630.8 \mathrm{eV}$, and the peaks of remaining $\mathrm{CH}_{3} \mathrm{I}$ reacted samples located in between the values above except the $104 \mathrm{ppbv} / 200$ case.

However, the spectra of the $104 \mathrm{ppbv} / 200 \mathrm{CH}_{3} \mathrm{I}$ adsorbed $\mathrm{Ag}^{0}$-Aerogel are significantly different. Both

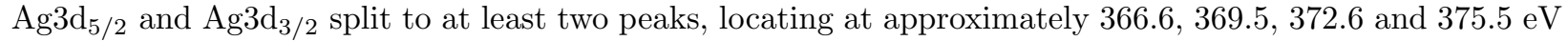
and $\mathrm{I}_{3} \mathrm{~d}_{5 / 2}$ and $\mathrm{I}_{3} \mathrm{~d}_{3 / 2}$ at $618.1,620.9,629.6$ and $632.4 \mathrm{eV}$. The variations of the $\mathrm{Ag}$ and I spectra at 104 ppbv/ 200 condition indicate the Ag-I compounds formed may be different.

The SEM-EDX analyses were also conducted to measure the element compositions and potential structure changes on the pellet surface. The SEM-EDX analyses were performed using JEOL JSM IT100LA at SUNY College of Environmental Science and Forestry (SUNY-ESF). The acceleration voltage was 10-15 kV and the probe current is $20-30 \mathrm{~mA}$ for secondary electron detector (SED) mode and 55-65 mA for backscattered electron composition (BEC) mode.

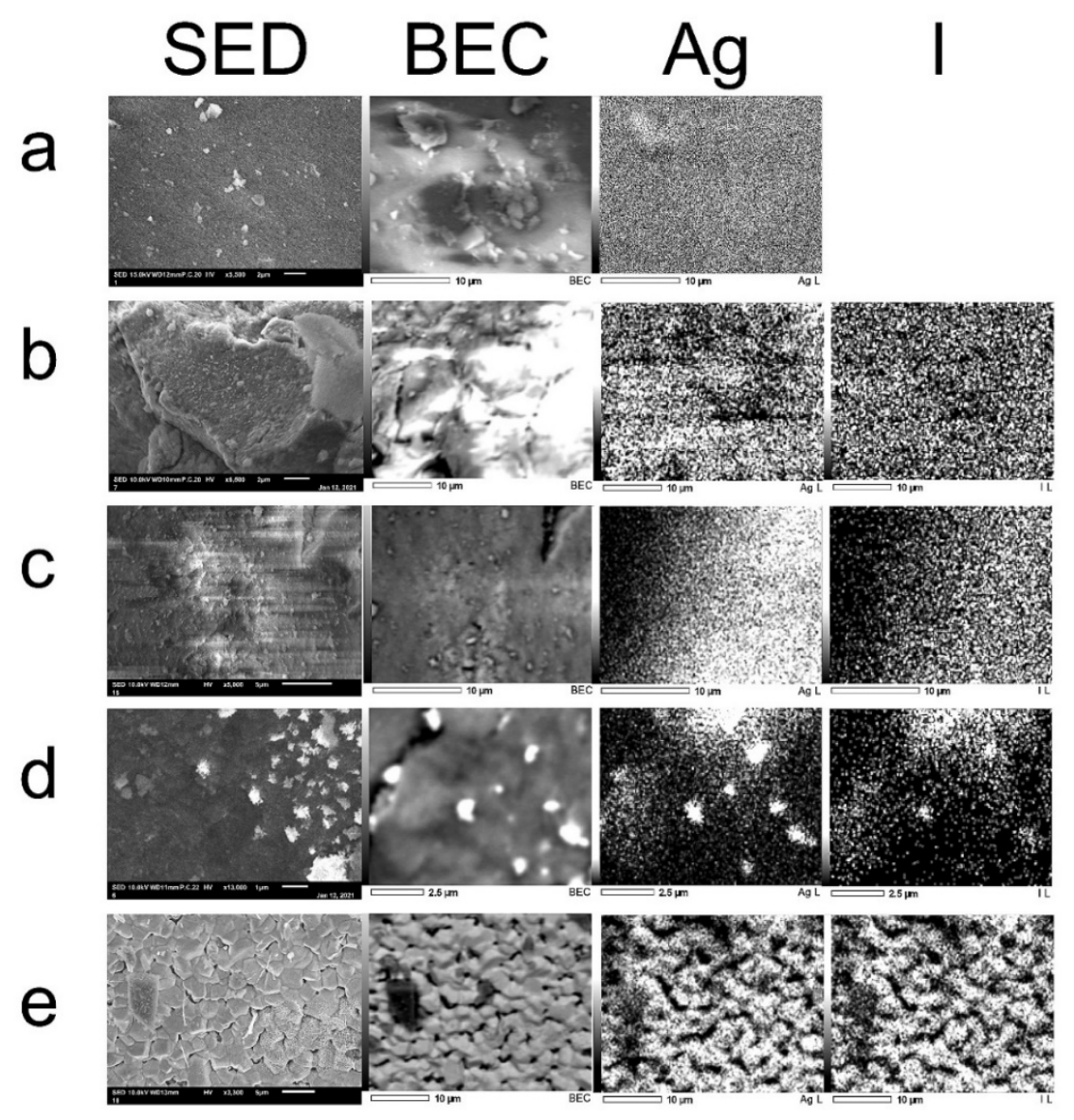


Figure 10. The SEM images including SED, BEC, Ag mapping and I mapping of (a) fresh, (b) 104 ppbv/150 $\mathrm{CH}_{3} \mathrm{I}$ partially loaded, (c) $1044 \mathrm{ppbv} / 150 \mathrm{CH}_{3} \mathrm{I}$ partially loaded, (d) $9585 \mathrm{ppbv} / 150 \mathrm{CH}_{3} \mathrm{I}$ fully loaded and (e) 50 ppmv /150 I $\mathrm{I}_{2}$ fully loaded $\mathrm{Ag}^{0}$-Aerogel. (Full resolution images are available in Supplementary Materials )

The SED and BEC (including the corresponding mappings of Ag and I) images are shown in Figure 10. The images show that the fresh $\mathrm{Ag}^{0}$-Aerogel (a) does not contain any notable $\mathrm{Ag}$ clusters in the micrometer scale on the surface. After reacting with 104 (b) and 1044 ppbv (c) $\mathrm{CH}_{3} \mathrm{I}$ (partially loaded), the surfaces of the adsorbent become coarser, whereas the distributions of $\mathrm{Ag}$ and I remain relatively uniform. As the concentration of the adsorbate increases, certain surface structures were formed and some bright spots can

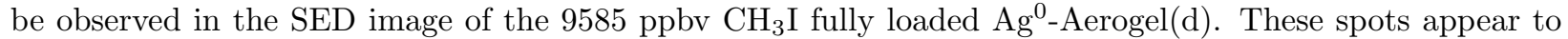
be AgI clusters since the same spots were also observed in the BEC image and the corresponding Ag and I mappings. The change of surface structure is more significant for the $50 \mathrm{ppmv} \mathrm{I}_{2}$ fully loaded sample. A layer consisting of AgI in polygon shape may be formed during the adsorption process.

\section{Surface Composition}

Observed in the XPS results (Figure 9), the spectra of 104 ppbv/ $200 \mathrm{CH}_{3} \mathrm{I}$ adsorbed $\mathrm{Ag}^{0}$-Aerogel are significantly different from all others, which may further explain the abnormal high uptake rate. Figure 11 is the $\mathrm{Ag}(\mathrm{a})$ and $\mathrm{I}(\mathrm{b})$ regional scans of the $104 \mathrm{ppbv} / 200 \mathrm{CH}_{3} \mathrm{I}$ adsorbed pellets with the spectra of $\mathrm{CH}_{3} \mathrm{I}$ fully loaded sample as references. Both Ag and I spectra of $104 \mathrm{ppbv} / 200$ sample consist of three groups of peaks, which are marked as 1, 2 and 3 in the figure. For Ag spectrum, 3 Ag3 $\mathrm{d}_{5 / 2}$ peaks are located at 366.6, 368.2 and $369.45 \mathrm{eV}$, which the second group is well agreed with the peaks of $\mathrm{CH}_{3} \mathrm{I}$ fully loaded sample. Similarly, the I spectrum also contains 3 groups of peaks and the binding energies of the second group are close to those of the fully loaded sample. The compositions of three groups of peaks were also determined, and the results are, approximately $52-55 \%, 15-20 \%$ and $28-29 \%$ for group 1, 2 and 3 respectively. Since the compositions acquired in both fittings are relatively similar, the additional peaks appear to be some form of Ag-I (not AgI, silver iodide) compounds.

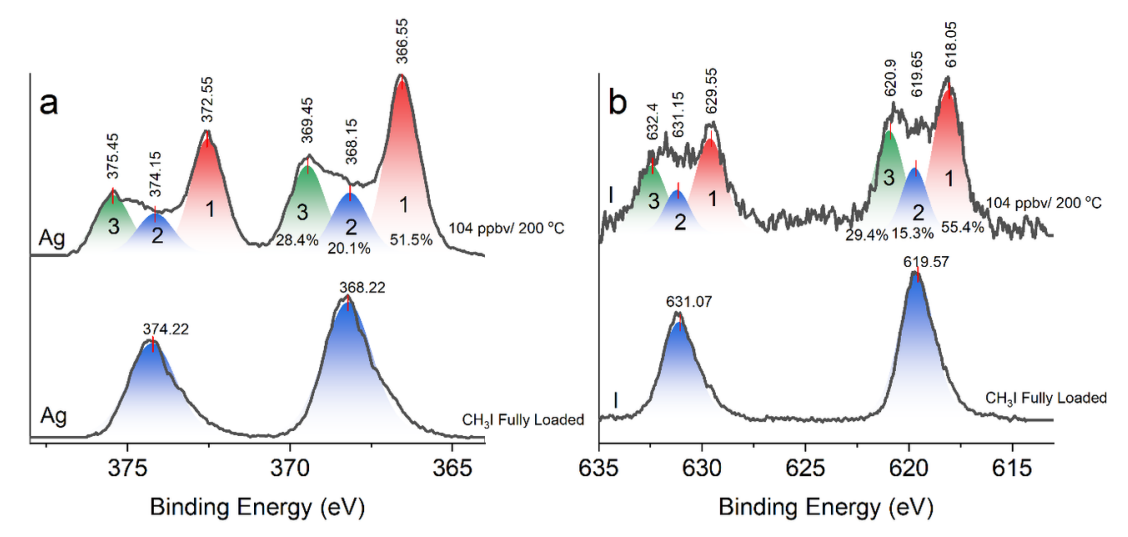

Figure 11. The regional scans of $\mathrm{Ag}(\mathrm{a}), \mathrm{I}(\mathrm{b})$ and the curve fits of the $104 \mathrm{ppbv} / 200 \mathrm{CH}_{3} \mathrm{I}$ adsorbed $\mathrm{Ag}^{0}$ Aerogel.

Reported in multiple studies, ${ }^{43-47}$ the Ag BE tends to decrease as the oxidation state increases. For example, the $\mathrm{Ag}_{3 / 2} \mathrm{BE}$ of metallic $\mathrm{Ag}$ is approximately 368.1, and this value decreases to $367.7-367.9 \mathrm{eV}_{5}$ for $\mathrm{Ag}^{+}$ and 367.3-367.6 eV for $\mathrm{Ag}^{2+}$. Admittedly, the instrument deviations and data calibration standards may vary the $\mathrm{BE}$ measured, but the trend indicates that a certain amount of $\mathrm{Ag}^{2+}$ may be formed in $104 \mathrm{ppbv}$ $\mathrm{CH}_{3} \mathrm{I}$ adsorption at 200 , whereas the peak group 3 remains questionable. 
The Ag and I concentrations can be interpreted from the XPS and SEM-EDX spectra, where the results are listed in Table 3. To compare the iodine concentrations between samples, the iodine compositions have been calibrated as additional mass, which the summations of all other elements are 100\%. It is important to noticed that the $\mathrm{Ag}^{0}$-Aerogel is a highly heterogeneous material; the $\mathrm{Ag}$ coverage on the pellets is uneven, and the values measured by SEM-EDX and XPS may vary based on the specific location scanned.

\section{Conditions}

\section{Temperature}

()

\section{SEM-EDX}

\section{SEM-EDX}

\section{SEM-EDX}

\section{SEM-EDX}

\section{XPS}

XPS

XPS

XPS

Iodine Uptake

(wt\%)

Ag (wt\%)

I (wt\%)

$\mathrm{I}: \mathrm{Ag}^{(2)}(\mathrm{mol})$

$\mathrm{I}: \mathrm{Ag}^{(3)}$ (wt)

Ag (wt\%)

I (wt\%)

$\mathrm{I}: \mathrm{Ag}^{(2)}(\mathrm{mol})$

$\mathrm{I}: \mathrm{Ag}^{(3)}(\mathrm{wt})$

Fresh

31.5

33.7

350 Degas

34.0

30.2

$\mathrm{CH}_{3}$ I F.L. ${ }^{(1)}$

150

29.1

32.3 
0.94

1.11

29.2

28.3

0.82

0.97

38.31

$\mathrm{I}_{2}$ F.L. (1)

150

26.9

27.1

0.86

1.01

37.24

104 ppb

100

39.0

0.9

0.02

0.02

27.7

1.8

0.05

0.06

0.29

150

38.5

1.2

0.03

0.03 
0.08

0.09

0.42

200

41.9

2.6

0.05

0.06

28.7

5.8

0.17

0.20

1.15

1044 ppb

100

40.6

4.8

0.10

0.12

27.9

6.0

0.18

0.21

2.84

150

34.3

5.0

0.12

0.15

27.8

12.4

0.38 
(1) Fully Loaded

(1) Fully Loaded

(2) Molar ratio of I and $\mathrm{Ag}$

(2) Molar ratio of I and $\mathrm{Ag}$

(3) Mass ratio of I and Ag

(3) Mass ratio of I and Ag

Table 3. The Ag and I concentrations measured by SEM-EDX and XPS (I compositions have been calibrated as additional mass).

Both SEM-EDX and XPS are the surface analysis techniques whereas the penetration depth of XPS is approximately 5-10 nm and that of SEM-EDX is 1-10 $\mu \mathrm{m} .{ }^{48,49}$ Therefore, the higher iodine compositions for partially loaded $\mathrm{Ag}^{0}$-Aerogel observed by XPS indicate the existence of a strong concentration gradient in the pellet during the $\mathrm{CH}_{3} \mathrm{I}$ adsorption. Additionally, it can also be visualized that the concentrations of I on the surface are much higher than the experimental measured iodine uptakes (same as $\mathrm{CH}_{3} \mathrm{I}$ uptake, assuming $\mathrm{CH}_{3}$ group diffuse out in $\mathrm{C}_{2} \mathrm{H}_{6}$ form), which further supports the existence of the surface reaction proposed by Tang et al. ${ }^{23}$

\section{Conclusion and Recommendation}

Traditionally, after the adsorption, $\mathrm{Ag}^{0}$-Aerogel will be consolidated by compressing at high temperature, and removing the organic moieties at 350 before compressing benefits the consolidation results (higher product density and lower porosity). ${ }^{25}$ In this presented work, a novel pre-treating method was applied. The $\mathrm{Ag}^{0}$-Aerogel was vacuum dried at 350 before the $\mathrm{CH}_{3} \mathrm{I}$ adsorption to remove the organic moieties, and the uptake rate and maximum iodine adsorption capacity remain similar to the untreated one. Therefore, removing the organic moieties before the adsorption could be a practicable alternative, and the potential iodine contamination during the traditional organic moieties removing process could be avoided.

In the 104 and 1044 ppbv $\mathrm{CH}_{3} \mathrm{I}$ adsorptions on $\mathrm{Ag}^{0}$-Aerogel at 100, 150 and 200 , an abnormal behavior was observed in $104 \mathrm{ppbv}$ adsorption at 200 ; the uptake rate was approximately 3 - 4 times higher than those of 100 and 150 adsorptions at the same concentration. The most intuitive explanation is the well-known Arrhenius relationship, the increase of temperature results in the increase of reaction rate and diffusivity. 
Additionally, more potential explanations are proposed based on successive experimental and theoretical analyses. The nitrogen adsorption analyses were performed using the pellets at different drying conditions, and the results indicated that the increasing temperature decreases the water concentration in the pellet and therefore may increase the silver sites availability and the pore diffusivities of $\mathrm{CH}_{3} \mathrm{I}$ and the gas form product. The gas form product, believed to be $\mathrm{C}_{2} \mathrm{H}_{6}$, is considered as a 'diffusion limitation' for the adsorption process in the proposed reaction pathway, and the increase of its diffusivity may vary the reaction rate in another perspective.

Moreover, the XPS and SEM-EDX analyses were also performed and the results indicated that at $104 \mathrm{ppbv/}$ 200 condition, some additional Ag-I compounds were generated. By comparing the binding energies of the peaks with previous studies, we presumed that the additional Ag-I compounds may contain a certain amount of $\mathrm{Ag}^{2+}$. However, identifying the peak group 3 in Figure 9 remains unsolved. To further determine the composition formed in $\mathrm{CH}_{3} \mathrm{I}$ adsorption process, performing additional physical analyses such as regional scans of other elements in XPS, x-ray absorption spectroscopy (XAS) and Raman spectroscopy is recommended.

In the presented work, we observed an unusually high uptake rate for $104 \mathrm{ppbv} \mathrm{CH}_{3} \mathrm{I}$ adsorption on $\mathrm{Ag}^{0}$ Aerogel at 200 , and suggested multiple explanations for this behavior. Our discoveries offer a new perspective in determining the optimum temperature for $\mathrm{CH}_{3} \mathrm{I}$ adsorptions, whereas a commonly used temperature is 150 . However, for the purpose of carefulness and accuracy, we may not recommend 200 as the optimum adsorption temperature until further evidence has been revealed.

\section{Acknowledgement}

This research was funded by the Nuclear Energy University Program of the U.S. Department of Energy, Office of Nuclear Energy (Grant No. DE-NE0008761). A portion of the presented work may be used in Siqi Tang's Ph.D. thesis and the technical report submitted to DOE.

\section{Literature Cited}

1. Office of Nuclear Energy. 9 Notable Facts About the World's First Nuclear Power Plant - EBR-I. 2019. Accessed Jan. 11, 2021.

2. Haefner DR, Tranter TJ. Methods of Gas Phase Capture of Iodine from Fuel Reprocessing Off-Gas: A Literature Survey. Technical Report No. INL/EXT-07-12299. Idaho National Laboratory, Idaho Falls, ID. 2007

3. Purkayastha BC, Martin GR. The yields of 129I in natural and in neutron-induced fission of uranium. Canadian Journal of Chemistry. 1956;34(3):293-300.

4. Jubin RT, Strachan D. Assessments and Options for Removal and Immobilization of Volatile Radionuclides from the Processing of Used Nuclear Fuel. Technical Report No. ORNL/SPR-2015/115. ORNL, Oak Ridge, TN. 2015

5. Bruffey SH, Jubin RT, Jordan JA. Capture of Elemental and Organic Iodine from Dilute Gas Streams by Silver-exchanged Mordenite.Procedia Chemistry. 2016;21:293-299.

6. Bruffey SH, Spencer BB, Strachan DM, Jubin RT, Soelberg NR, Riley BJ. A literature survey to identify potentially problematic volatile iodine-bearing species present in off-gas streams. Technical Report No. ORNL-SPR-2015/290. ORNL, Oak Ridge, TN. 2015

7. Jubin RT, Bruffey SH, Spencer BB. Performance of Silver-exchanged Mordenite for Iodine Capture under Vessel Off-gas Conditions. Technical Report No. DE-AC05-00OR22725. ORNL, Oak Ridge, TN. 2015

8. Henrich E, Schmieder H, Roesch W, Weirich F. Improved iodine and tritium control in reprocessing plants. Paper presented at: 16th DOE Nuclear Air Cleaning Conference. 1981; The Harvard Air Cleaning Laboratory, Cambridge, MA 
9. Sakurai T, Komaki Y, Takahashi A, Izumo M. Applications of zeolites to remove iodine from dissolver offgass, (III) Adsorption of methyl iodide $\left(\mathrm{CH}_{3} \mathrm{I}^{*}\right)$ on zeolite 13X. Journal of Nuclear Science and Technology. 1983;20(12):1046-1047.

10. Nakamura K, Saeki M, Tachikawa E. Formation of Organic Iodides upon Heating Nitric Acid Solutions Containing Carrier-Free lodine-131.Journal of Nuclear Science and Technology. 1973;10(6):367-373.

11. Matyáš J, Fryxell G, Busche B, Wallace K, Fifield L. Functionalised silica aerogels: Advanced materials to capture and immobilise radioactive iodine. Paper presented at: Ceramic Engineering and Science Proceedings. 2011

12. Jubin RT. The mass transfer dynamics of gaseous methyl-iodide adsorption by silver-exchanged sodium mordenite [Dissertation]. Knoxville, The University of Tennessee; 1994.

13. Nan Y. Adsorption of Iodine and Water on Silver-Exchanged Mordenite [Dissertation]. Syracuse University; 2017.

14. Jordan JA, Jubin RT. Stability of Tritium and Iodine Sorbents under Tritium-Pretreatment Off-Gas Conditions. Technical Report No. ORNL/SR-2017/162. ORNL, Oak Ridge, TN. 2017

15. Zou H, Yi F, Song M, et al. Novel synthesis of $\mathrm{Bi}^{-} \mathrm{Bi}_{2} \mathrm{O}_{3}-\mathrm{TiO}_{2}-\mathrm{C}$ composite for capturing iodine-129 in off-gas. Journal of Hazardous Materials. 2019;365:81-87.

16. Chee T-S, Tian Z, Zhang X, Lei L, Xiao C. Efficient capture of radioactive iodine by a new bismuthdecorated electrospinning carbon nanofiber. Journal of Nuclear Materials. 2020;542:152526.

17. Scott SM, Hu T, Yao T, Xin G, Lian J. Graphene-based sorbents for iodine-129 capture and sequestration. Carbon. 2015;90:1-8.

18. He L, Chen L, Dong X, et al. A nitrogen-rich covalent organic framework for simultaneous dynamic capture of iodine and methyl iodide. Chem. 2020.

19. Falaise C, Volkringer C, Facqueur J, Bousquet T, Gasnot L, Loiseau T. Capture of iodine in highly stable metal-organic frameworks: a systematic study. Chemical Communications.2013;49(87):10320-10322.

20. Matyáš J, Ilton ES, Kovař́k L. Silver-functionalized silica aerogel: towards an understanding of aging on iodine sorption performance. RSC advances. 2018;8(56):31843-31852.

21. Scheele RD, Burger LL, Matsuzaki CL. Methyl iodide sorption by reduced silver mordenite. Technical Report No. PNNL-4489. Pacific Northwest National Laboratory. 1983

22. Zhou XL, Solymosi F, Blass PM, Cannon KC, White JM. Interactions of methyl halides (Cl, Br and I) with $\operatorname{Ag}(111)$. Surface Science.1989;219(1):294-316.

23. Tang S, Choi S, Nan Y, Tavlarides LL. Adsorption of Methyl Iodide on Reduced Silver-Functionalized Silica Aerogel: Kinetics and Modeling.AIChE Journal. 2020:e17137.

24. Nan Y, Tavlarides LL, DePaoli DW. Adsorption of iodine on hydrogen-reduced silver-exchanged mordenite: Experiments and modeling. AIChE Journal. 2017;63(3):1024-1035.

25. Matyaš J, Engler RK. Assessment of Methods to Consolidate Iodine-Loaded Silver-Functionalized Silica Aerogel. Technical Report No. PNNL-22874, AF5805000. Pacific Northwest National Lab. (PNNL), Richland, WA. 2013

26. Levenspiel O. Chemical Reaction Engineering. New York, NY: John Wiley \& Sons. 1972.

27. Fuller EN, Ensley K, Giddings JC. Diffusion of halogenated hydrocarbons in helium. The effect of structure on collision cross sections. The Journal of Physical Chemistry.1969;73(11):3679-3685.

28. Talu O, Sun MS, Shah DB. Diffusivities of n-alkanes in silicalite by steady-state single-crystal membrane technique. AIChE Journal.1998;44(3):681-694. 
29. Soares JL, Moreira RFPM, José HJ, Grande CA, Rodrigues AE. Hydrotalcite Materials for Carbon Dioxide Adsorption at High Temperatures: Characterization and Diffusivity Measurements.Separation Science and Technology. 2005;39(9):1989-2010.

30. Balkis Ameen K, Rajasekar K, Rajasekharan T. Silver Nanoparticles in Mesoporous Aerogel Exhibiting Selective Catalytic Oxidation of Benzene in $\mathrm{CO}_{2}$ Free Air. Catalysis Letters.2007;119(3):289-295.

31. Currie JA. Gaseous diffusion in porous media. Part 3 - Wet granular materials. British Journal of Applied Physics.1961;12(6):275-281.

32. Zhou XL, White JM. Thermal decomposition of $\mathrm{C}_{2} \mathrm{H}_{5} \mathrm{I}$ on $\mathrm{Ag}(111)$. Catalysis Letters. 1989;2(6):375-384.

33. Robb DA, Harriott P. The kinetics of methanol oxidation on a supported silver catalyst. Journal of Catalysis.1974;35(2):176-183.

34. Fogler HS. Elements of chemical reaction engineering. New Jersey: Prentice Hall; 2016.

35. Arrhenius S. Über die Dissociationswärme und den Einfluss der Temperatur auf den Dissociationsgrad der Elektrolyte. Zeitschrift für physikalische Chemie. 1889;4(1):96-116.

36. Park S, An H, Park MB, Lee J. Adsorption behavior of methyl iodide on a silver ion-exchanged ZSM-5. Microporous and Mesoporous Materials. 2020;294:109842.

37. Lente G, Fábián I, Poë AJ. A common misconception about the Eyring equation. New Journal of Chemistry. 2005;29(6):759-760.

38. Lesclaux R, Khê PV, Dezauzier P, Soulignac JC. Flash photolysis studies of the reaction of NH2 radicals with NO. Chemical Physics Letters. 1975;35(4):493-497.

39. Benson SW, Dobis O. Existence of Negative Activation Energies in Simple Bimolecular Metathesis Reactions and Some Observations on Too-Fast Reactions. The Journal of Physical Chemistry A.1998;102(27):51755181 .

40. Kindel O, Hoeflich V, Herrmann FJ, Patzelt P. Removal of iodooraganic compounds from kerosene in nuclear fuel reprocessing. Journal of Radioanalytical and Nuclear Chemistry.1993;176(3):251-259.

41. Zhang W, Zhang L, Hui Z, Zhang X, Qian Y. Synthesis of nanocrystalline $\mathrm{Ag}_{2} \mathrm{~S}$ in aqueous solution. Solid State Ionics. 2000;130(1):111-114.

42. Hota G, Idage SB, Khilar KC. Characterization of nano-sized CdS- $\mathrm{Ag}_{2} \mathrm{~S}$ core-shell nanoparticles using XPS technique. Colloids and Surfaces A: Physicochemical and Engineering Aspects.2007;293(1):5-12.

43. Tomaszewicz E, Kurzawa M. Use of XPS method in determination of chemical environment and oxidation state of sulfur and silver atoms in $\mathrm{Ag}_{6} \mathrm{~S}_{3} \mathrm{O}_{4}$ and $\mathrm{Ag}_{8} \mathrm{~S}_{4} \mathrm{O}_{4}$ compounds. Journal of materials science. 2004;39(6):2183-2185.

44. Wolan JT, Hoflund GB. Surface characterization study of $\mathrm{AgF}$ and $\mathrm{AgF}_{2}$ powders using XPS and ISS. Applied Surface Science. 1998;125(3):251-258.

45. Schön G, Tummavuori J, Lindström B, Enzell CR, Swahn CG. ESCA studies of $\mathrm{Ag}, \mathrm{Ag}_{2} \mathrm{O}$ and $\mathrm{AgO}$. Acta Chem Scand.1973;27(7):2623.

46. Hoflund GB, Weaver JF, Epling WS. Ag2O XPS Spectra. Surface Science Spectra. 1994;3(2):157-162.

47. Briggs D, Seah MP. Practical surface analysis: by Auger and X-ray photoelectron spectroscopy. Wiley. 1983.

48. Morent R, De Geyter N, Leys C, Gengembre L, Payen E. Comparison between XPS- and FTIR-analysis of plasma-treated polypropylene film surfaces. Surface and Interface Analysis. 2008;40(3-4):597-600. 
49. Onoue F, Tsuji K. X-Ray Elemental Imaging in Depth by Combination of FE-SEM-EDS and Glow Discharge Sputtering. ISIJ International.2013;53(11):1939-1942. 